\title{
A REFORMA DA PREVIDÊNCIA ${ }^{1}$
}

Wilson Cano

Boa tarde a todos, eu quero agradecer o convite do Serviço Social do Hospital das Clínicas. Bom, antes de entrar na reforma propriamente dita é necessário explicar que a reforma da previdência, assim como uma série de outras reformas às quais eu vou me referir, fazem parte de um conjunto de reformas institucionais e estruturais que vêm sendo impostas no tratamento aos países subdesenvolvidos a partir de meados da década de 1980 que é um período crucial na economia mundial, de países com crises financeiras pesadas, pelo desmoronamento da União Soviética e por uma série de fatos que tiveram repercussões políticas, econômicas e sociais que alteraram significativamente o mundo como nós o conhecíamos.

O que são estas reformas? As transformações fundamentais pelas quais passaram grandes empresas transnacionais dos principais países desenvolvidos e a crise financeira internacional, esses dois fatos, passaram a exigir nos anos 90 que os países subdesenvolvidos abandonassem ou flexibilizassem o máximo a possibilidade da entrada de mercadorias produzidas pelas transnacionais em todos os países de origem, e a entrada e saída quase que livre do capital financeiro internacional dessas empresas e bancos transnacionais. Porque, só assim poderiam dar vazão aos enormes excessos de produção que eles tinham, através da abertura dos nossos mercados. Parte disso é resolvido com a abertura dos nossos mercados financeiros, e até apelidei o capital financeiro que vem para cá de “capital motel” porque ele chega de “mansinho” na sexta-feira e se possível ele já sai de madrugada, ou seja, ele não perde muito tempo, vem hoje, toma o dinheiro lucrado e sai correndo.

Essas reformas foram as reformas que permitiram a liberalidade do capital internacional: a financeira, a da abertura comercial, com eliminação ou forte redução da tarifa de importação e de restrições às importações das mercadorias em geral. As reformas

\footnotetext{
${ }^{1}$ Mesa Redonda Assistência e Previdência: Caminhos e tendências no XX Ciclo de Debates do Serviço Social do Hospital das Clínicas da UNICAMP. Expositores: Professor Dr. Wilson Cano do Instituto de \begin{tabular}{lllll}
\hline Serviço Social \& Saúde & Campinas & v. 3 & n. 3 & p. 1-94 Maio 2004
\end{tabular}
} 
do Estado, porque para fazê-las, era preciso evidentemente abalar o poder do Estado Nacional. Então têm todo um discurso de que o Estado dos países subdesenvolvidos era um Estado gigantesco, era um Estado de desperdício, era um Estado que tinha muito funcionário público, era um Estado que tinha muitas empresas estatais, e que era preciso privatiza-las.

Esse foi o discurso criado em Washington e transmitido principalmente pelo Fundo Monetário Internacional e pelo Banco Mundial. As duas reformas fazem parte desse conjunto e, do jeito que foram propostas, elas abalam o poder do Estado Nacional para facilitar exatamente essas livres entradas e saídas. As outras duas liberam o mercado de mercadorias, e o mercado de dinheiro. Duas outras, próximas, terão como objetivo a contenção ou redução do custo do trabalho, que são as reformas trabalhista e a sindical. Mas, já existem vários ensaios, já existe alguma coisa que está sendo dita, como por exemplo uma coisa que é um horror que alguém, com inteligência, com uma formação superior, possa formular. Há uma proposta sórdida que pretende fazer com que os trabalhadores das micro empresas, das pequenas empresas possam ser tratados pela mesma legislação que dá cobertura ao trabalho da empregada doméstica, ou seja, quase nada. Essa é a uma das propostas da reforma trabalhista, e queira Deus que não vingue.

E a última é a reforma da previdência que tem objetivos um pouco mais sutis. Um deles é privatizar a Previdência Social e retirá-la da órbita do Estado para criar, evidentemente, mais uma possibilidade interessante para os capitais privados nacionais e internacionais engordarem mais do que já engordam. A outra, ao retirar isso da órbita do Estado, cria um espaço para que os juros sobre as dívidas externas e internas públicas possam ser intimamente pagos. É isso que tem constituído, na verdade, as políticas dos últimos 20 anos: se corta aqui, se corta ali, se corta aqui, se corta ali, se corta da saúde, se corta da educação, aumenta o buraco da estrada, para que? Simplesmente para dar guarida a um montante crescente de juros sobre as nossas dívidas.

Economia da UNICAMP e Professora Dra. Maria Carmelita YazbeK Coordenadora da Pós-Graduação em Serviço Social da PUC São Paulo.

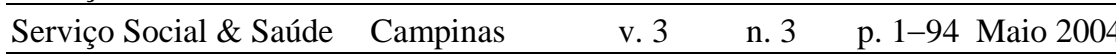


Então, promovendo um superávit, ou seja, um resultado positivo entre a receita do Estado e o gasto, em torno de 4,25\% do PIB. As pessoas que não entendem isso dizem: caramba, estamos economizando 4\%! E, isso não é mentira, estamos economizando 4,25\%, mas estamos pagando 9\% desse mesmo PIB, pelo montante dos juros de toda a dívida pública interna e externa! Não se paga impostos gigantes com cortes nos gastos, com cortes de salários dos funcionários públicos, como está decorrrendo dessa reforma, como está sendo feita a reforma previdenciária. Isso se faz, justamente para que "sobre” única e exclusivamente um espaço para o pagamento dos juros. E é nisso que está consistindo a política econômica dos últimos 20 anos, no pagamento dos juros. Essas políticas passaram a vigorar a partir de março de 1990 já com o governo Collor.

No que consiste o projeto da nossa reforma da previdência? Eu nunca estudei previdência social. Eu fui estudar o problema da previdência porque simplesmente fiquei indignado quando isso começou a ser divulgado pela imprensa. Por que? Porque o governo botou na imprensa um número de todo o déficit da previdência em torno de 75 bilhões de reais e, com a opinião pública "trabalhada”, e muito bem trabalhada por jornais e televisões começam então a difundir a falsa idéia de que "os males desse país são os funcionários públicos, esse vagabundos, picaretas, privilegiados que ganham demais, não trabalham, e ainda têm uma aposentadoria integral; que injustiça! É preciso que nós acabemos com essa injustiça!”

Muito bem, isso me indignou profundamente e fui então examinar as contas da previdência. Em primeiro lugar, constitui uma grande maldade se misturar num só balaio o INSS, com a Previdência Pública Federal, com os vinte sete casos diferentes de Previdência Públicas Estaduais e com cinco mil e quinhentos casos diferentes de Previdências Públicas Municipais. Cada um desses casos é um caso, tem uma história, tem um problema e, obviamente, deve ser contemplado com o tipo de reforma para o seu enfrentamento concreto.

Verifiquei portanto que as contas do INSS apresentavam no ano passado, efetivamente, um buraco de dezessete bilhões. Então, eu retirei dos 75 bilhões os 17 bilhões da previdência pública, sobraram 58 bilhões. Bom, destes, verifiquei que na verdade aquilo 
que dizia respeito ao funcionalismo público federal eram apenas 35 bilhões e portanto o restante era problemas dos Estados e de Municípios.

Então, os 75 bilhões você já quebra em três pedaços, e portanto a opinião pública disse: "Então, os funcionários públicos, os malditos funcionários públicos federais são responsáveis pelos trinta e cinco bilhões e não por setenta e cinco bilhões, os outros responsáveis são os malditos trabalhadores que estão todos no INSS”.

Bom, fui examinar as contas do INSS, porque as contas do INSS começam a ficar desequilibradas a partir de 1990 e, principalmente, a partir de 1995. Primeira razão, o país não vem crescendo. Segunda razão, o desemprego cresceu muito, dobrou. Terceira razão, o salário médio real do trabalhador brasileiro teve uma queda de 15 a 20\%. Quarta razão, parte daqueles que foram desempregados ou que sequer foram empregados com uma carteira assinada, arranjaram emprego em ocupações informais, sem carteira assinada e, portanto, sem Previdência Social. Isto não é culpa de ninguém nem do funcionário público, nem do INSS, é um problema exatamente que o culpado único é o governo que tem promovido políticas econômicas que impedem o crescimento e o desenvolvimento do país e o aumento da ocupação e a melhoria do salário da população.

Segunda questão, constatei porque existe o orçamento que chama-se Orçamento da Seguridade Social que se compõe não apenas das contribuições previdenciárias, mas de uma série de outras contribuições, principalmente, da COFINS.

Se nós pegarmos o ano de 2002 e examinarmos quanto foi arrecadado por todas as contribuições e quanto foi gasto, nós vamos verificar que há uma sobra de quase 33 bilhões de reais, mais do que o dobro do buraco alegado para o INSS. Portanto, o governo não tem nenhuma razão para dizer que a Previdência Geral do INSS é deficitária, que está causando um impacto no orçamento público. É mentira, é mentira porque ele está arrecadando muito mais em termos de contribuições de seguridade social do que ele tem gasto.

Mas é que tem outros problemas piores ainda por traz disso: na conta da Previdência do INSS estão incluídos 18 milhões idosos e se a Constituição de 88 não tivesse dado conta deles e mandado pagar um salário mínimo essa gente teria morrido,

\begin{tabular}{llllll}
\hline Serviço Social \& Saúde & Campinas & v. 3 & n. 3 & p. 1-94 Maio 2004
\end{tabular}


simplesmente nós teríamos além dos nossos 45 ou 50 milhões de pobres em todo o país, mais esses 18 milhões. Dezoito milhões a mais de famintos se não fosse a generosidade da Constituição de 88. Só que essa gente, nunca pagou um centavo para a Previdência Social e, portanto, não posso incluí-los como elementos integrantes da Previdência. Eles têm que estar numa conta de Assistência Social e não de Previdência Social.

Eu pergunto porque os diferentes governos têm permitido que anualmente cerca de 10 bilhões de reais não sejam recolhidos pelo INSS: é clube de futebol, são PUCs, é Clube de Lar Santa Terezinha e várias instituições que se fazem valer de isenções e prerrogativas e não recolhem suas contribuições previdenciárias. Não recolhe a previdência do seu trabalhador, mas ele vai se aposentar um dia e, portanto, ele vai cobrar da INSS a aposentadoria dele. Se não entra dinheiro nessa caixa, como que eu posso tirar dela? E a dívida que empresários privados e de vários órgãos públicos que têm com INSS que ninguém cobra (160 bilhões de reais!), a incúria administrativa, a incompetência, a irresponsabilidade e a maldita política de encolhimento do Estado. É uma vergonha o estado da previdência que nós temos. É vergonhoso, por exemplo para vocês terem uma idéia: o Brasil tem hoje na delegacia da Receita Federal, no Imposto de Renda, cerca de cinco mil e cinco mil e quinhentos fiscais, a Itália tem oitenta mil, a Alemanha tem cem mil, os Estados Unidos tem cento e cinqüenta mil fiscais, entretanto "olha quantos funcionários públicos vagabundos que tem nesse país”, por isso não se arrecada mais do que tem que se arrecadar.

Então a dívida do INSS é simplesmente uma mentira, é uma forma de mascarar e alegar que tem um buraco de 17 quando não tem buraco de 17.Por exemplo, se eu retirar os idosos que estão na conta do INSS só eles somam quase 15 bilhões de reais, aos preços do ano passado. E se for descontar dos 17 bilhões sobram apenas 2 bilhões.

E na Previdência Pública Federal como é a história? As contas são igualmente vergonhosas, por que? E o governo vem à opinião pública e diz: 35 bilhões é quanto nos custam os inativos e pensionistas. Só que ele "esqueceu” de descontar destes trinta e cinco aquilo que os funcionários públicos já perdem no guichê, que é a Contribuição à Previdência Social, que soma quase 4 bilhões de reais. Somando não é mais trinta e cinco,

\begin{tabular}{lllll}
\hline Serviço Social \& Saúde & Campinas & v. 3 & n. 3 & p. 1-94 Maio 2004 \\
\hline
\end{tabular} 
caiu para trinta e um. O governo também “esqueceu” de descontar nessa conta aquilo que ele deveria ter pago, que é a contribuição previdenciária do patrão - deveria ser o dobro da contribuição previdenciária do trabalhador - que só aí, seriam mais 8 bilhões. E se ele não estivesse “esquecido” disso a nossa conta baixaria para 23 e não mais 35.

Só que aí tem mais um artigo no projeto da reforma previdenciária, o presidente dá um tratamento diferenciado especial aos militares. Eu não tenho nada contra isso, sejam militares, sejam outros segmentos do funcionalismo que a sociedade julgar ser merecedor de um tratamento especial. Muito bem, mas então tiremos os militares do balaio dos funcionários públicos civis, e aí quando eu tiro, aquele número mágico de 35 cai para 12! Então, vejam vocês a coisa: era 75; caiu para 58; caiu para 12, mas lamentavelmente os jornais e a televisão continuam a reproduzir os 75 . Todos os dias eles martelam a opinião pública, apoiando a proposta do governo. Mas, por que a apoiam?

Porque nesta sociedade eu aprendi desde criança que a classe média, mais ainda os segmentos mais baixos da classe média, foram educados, melhor dizendo, mal educados para achar que o funcionário público é um privilegiado social é um pilantra, é um vagabundo que arranjou emprego através de um tio poderoso, é amante do Deputado, é o sobrinho de não sei quem. Também amplos segmentos da classe operária pensam isso. Então o funcionário público neste país é sinônimo de picareta, de vigarista. Então, tem um ódio, um preconceito arraigado da pequena classe média contra o funcionário público. Eles odeiam o funcionário público. Isso o governo soube explorar muito bem e a opinião pública também explorou muito bem.

O projeto do P.T. não é de hoje, que fique claro que eu estou fazendo uma crítica ao partido, eu pertenço ao Partido dos Trabalhadores, mas as opções que se faziam no partido há mais de dez anos, não traziam a tributação para os aposentados, nem o corte de $30 \%$ na pensões, nem a quebra da paridade. A discussão interna era outra: então esse projeto faz tudo isso. Depois eu vou apresentar com um pouco mais de detalhes os problemas eminente da reforma previdenciária.

Eu perguntei no primeiro debate que tive com o Ministro "Mas, Ministro, quer dizer que o problema da justiça social, eu sou funcionário público ganho $\mathrm{R} \$ \mathrm{X}$, eu me \begin{tabular}{lllll}
\hline Serviço Social \& Saúde & Campinas & v. 3 & n. 3 & p. 1-94 Maio 2004
\end{tabular} 
aposento e contínuo ganhando os $\mathrm{R} \$ \mathrm{X}$, o coitadinho lá do gerente não sei da onde que também ganha os mesmos $\mathrm{R} \$ \mathrm{X}$, ele se aposenta e vai receber no máximo, o limite fixado pelo INSS (hoje seriam R\$ 1.800). Coitadinho! Mas Ministro, eu contribui a minha vida inteira com $11 \%$ sobre o meu salário integral, e ele contribuiu a vida inteira com os $11 \%$ sobre, no máximo, $\mathrm{R} \$ 1.800$. Porque o governo não libera o teto do INSS e permite aos trabalhadores da Previdência em geral que recolham o quanto quizerem, e com isso o governo acaba com essa injustiça, pois se os dois contribuíram de uma maneira igual têm direito a receber exatamente a mesma importância”. O Ministro riu... É falso o argumento por eles usado de que buscam uma equidade maior; é um argumento totalmente falso, é um argumento mentiroso.

O governo também não explica à opinião pública o que aconteceu com o funcionalismo público federal entre 1990 com o dilúvio Collor e 2002. E não explica por exemplo que existiam quase um milhão de funcionários públicos federais e em 2002 esse número baixou para oitocentos mil. Mas não explica que o número de aposentados dobrou, exatamente por causa do pavor causado pelas reformas Collor e depois pelo pavor causado pela reforma anunciada por Fernando Henrique Cardoso. O pessoal correu e se aposentou. Então, na folha passou a ter quase 600 mil aposentados inativos, na folha federal, que não existiam, e disso ninguém fala.

Em que consiste a reforma? A reforma basicamente vai tocar nos seguintes pontos fundamentais, e eu estou me valendo apenas do que foi aprovado na Câmara Federal dado que a votação das emendas do Senado ainda não foi feita. Era para ter sido feito ontem, mas a oposição ao governo conseguiu adia-la. Não se sabe muito bem se o projeto vai chegar a ser votado este ano. Tem muita gente envolvida, há uma rebelião dentro do próprio partido, o senador Paim já disse que mandou registrar em cartório e se o governo não permitir negociação da emenda nesse partido, o senador Paim não é nenhum maluquete, nenhum radical. Não pode ser comparado a um outro Deputado ou Senadores mais radicais, ele é bastante moderado.

Fundamentalmente a primeira é a contribuição dos inativos em que todos vão pagar, tanto os que estão aposentados hoje quantos os que vierem a se aposentar, e receber 
acima pelo menos do nível de $\mathrm{R}$ \$ 2.400; o que passar desse valor, será tributado em $11 \%$. Segundo ponto, é a quebra da paridade, eu me aposentava e continuava ganhando exatamente o mesmo salário da mesma função na ativa. Os novos funcionários públicos não vão ter paridade, os atuais que não preencheram os requisitos da emenda 20 de 1998 também não vão ter mais paridade e a paridade vai ser discutida, ou talvez mantida apenas para os que já são aposentados hoje antes da promulgação da emenda 40 que está tramitando. Talvez alguns, que na transição da emenda de 98 eventualmente preencham os requisitos constando daquela emenda, que era a manutenção da idade de 60 a 55, 35 e 30 de contribuição, 20 de emprego público, 10 na mesma carreira e cinco no mesmo cargo, o que já é um fator extremamente limitativo para que alguém sejam contemplado com isso.

Terceiro ponto, é a quebra da integralidade. O que é integralidade? E receber um salário, que contempla a paridade, e era mantido integral, era intocável. Isso também já foi por água abaixo, todos novos aposentados e pensionista perderam a integralidade. $\mathrm{O}$ governo promete mudar essa emenda corrigindo anualmente os proventos da aposentadorias e pensões, só que ninguém sabe evidentemente quando vai ser feito essa correção, qual é o índice que vai ser usado, porque isso vai ser regulado não por uma emenda constitucional e sim por uma lei ordinária. A emenda constitucional requer no mínimo os votos de 2/3 do Congresso Nacional para aprová-la. A lei ordinária é diferente, a exigência para sua aprovação é consideravelmente menor de que uma medida constitucional.

As pensões atuais serão reduzidas também para chegar no máximo até 2400 mil e o que exceder isso perderá $70 \%$ do valor. Há aqui uma flagrante injustiça porque no mesmo balaio se jogou uma pessoa que ganha 2500 e 3000 mil reais e outro 30, os dois vão ser penalizados em $30 \%$ do que ganham, quando na verdade o governo perdeu uma excelente oportunidade para fazer uma curva progressiva, ou seja, tributasse mais pesadamente quem ganha mais e menos quem ganha menos. Claro que existem pensões muito altas (cerca de R\$ 20.000), e isso poderia ser mais pesadamente tributado, e isso é muito mais do que ganha a viúva de um professor da UNICAMP, que ganha muito menos.

\begin{tabular}{lllll}
\hline Serviço Social \& Saúde & Campinas & v. 3 & n. 3 & p. 1-94 Maio 2004 \\
\hline
\end{tabular} 
O último e quinto ponto crucial é a questão do teto, o teto que vai limitar o salário. E aqui é outra coisa porque a Constituição de 1988 já tinha previsto nas disposições transitórias no artigo 17, já havia previsto e aberto a porta para o governo tomar medidas para conter o salário dos marajás. Porque tem gente neste país que ganha salários inacreditavelmente elevados que são uma minoria. São uma minoria, mas que devia ser proibida evidentemente. É uma minoria acobertada através de questão na justiça que a pessoa entra na justiça e ganha.

Mas o contrário disto é o que fez o senhor Fernando Henrique, alterou a Constituição de 88 e fez com que o teto que antes da Constituição de 88 era dado pelo salário do Presidente da República, o teto fosse mudado para os ministros do Supremo Tribunal Federal, e hoje, a razão entre esses dois salários, é de um para dois e com isso o Supremo ganha duas vezes mais que o salário efetivo do Presidente da República. Com isso ao invés de coibir abusos, se criou mais um privilégio enorme.

A ementa 40 tem a pretensão de que os funcionários municipais deverão ter como limite o salário do prefeito, os funcionários estaduais, do executivo, os salários do governador, o legislativo, o salário dos Deputados Estaduais e os judiciários terão como limite 90\% do salário dos Ministros do Supremo Tribunal Federal. Então, na verdade você já cancelou esses diferenciais do salário da economia. Então, a proposta que alegava ser restauradora da justiça social, vai chancelar, na verdade, a brutal diferença dos salários que tinha nesse país.

Outro ponto da razão pela qual ela está sendo criada é para reduzir o déficit público. Isto é uma grande bobagem por que a economia que o Governo Federal vai fazer é muito pequena. A economia orçamentária que o governo quer fazer com a promulgação da emenda 40, está muito pequena e eu disse ao Ministro da Previdência num debate e ao vice Ministro da Previdência num outro debate, que eles estavam fazendo um trabalho de açougueiro; de que há sangue para tudo quanto é lado, e, na verdade existem outros métodos para se fazer isso. Tem uma conta na economia, que chama engenharia financeira para capitalização da previdência e com isso eles poderiam fazer a capitalização da previdência. Por que? Porque a Previdência Social virou um saco mágico, que há mais de 
cinqüenta anos o governo "mete a mão no saco" da Previdência faz aquele viaduto, faz aquele e prédio, aquela avenida, aquela estrada, aquele hospital e ninguém cobra isso. Ninguém nunca cobrou isso. Isto não é um passivo que é devido pelos funcionários públicos, é um passivo que é devido por uma incompetência, por uma ausência de responsabilidade do Estado Nacional, portanto a discussão da reforma da Previdência deveria ter um outro âmbito de discussão. Eu fico por aqui. Muito obrigado! 